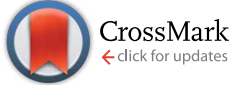

Cite this: RSC Adv., 2016, 6, 67954
Received 2nd April 2016

Accepted 1st July 2016

DOI: $10.1039 / \mathrm{c} 6 \mathrm{ra0} 8487 \mathrm{~g}$

www.rsc.org/advances

\section{Synergistic effect on static and dynamic mechanical properties of carbon fiber-multiwalled carbon nanotube hybrid polycarbonate composites $\uparrow$}

\author{
Arun Singh Babal, Bhanu Pratap Singh, ${ }^{\star}$ Jeevan Jyoti, Sushant Sharma, \\ Abhishek Kumar Arya and Sanjay R. Dhakate
}

\begin{abstract}
Carbon fiber (CF) and multiwalled carbon nanotube (MWCNT)-reinforced hybrid micro-nanocomposites are prepared through melt mixing followed by injection moulding. The synergistic effect on both the static and dynamic mechanical properties with MWCNT/aMWCNT and CF reinforcement in a polycarbonate matrix is investigated by utilizing dynamic mechanical analysis, and flexural and tensile measurements. The enhancement in the flexural modulus and strength of the composite specimens as compared to pure PC for maximum loading of CF is $128.40 \%$ and $39.90 \%$, respectively, which further improved to $142.94 \%$ and $42.60 \%$, respectively, for CF-functionalized MWCNTs. Similarly, the storage modulus of the composite specimens reinforced with a maximum loading of CF and CF-functionalized MWCNTs show an increment of $176.57 \%$ and $203.33 \%$, respectively over pure $\mathrm{PC}$ at $40{ }^{\circ} \mathrm{C}$. Various types of parameter such as the coefficient $C$ factor, degree of entanglement and adhesion factor have been calculated to analyze the interaction between fillers and the polymer matrix. Composite specimens containing $2 \mathrm{wt} \%$ of functionalized MWCNTs show a lower $C$ value than the as-synthesized MWCNTs, which is indicative of a higher effectiveness of functionalized MWCNT-containing composite specimens. These results are well supported by optical microscopy and Raman spectroscopy by confirming the distribution of reinforcements and the interaction to PC, respectively.
\end{abstract}

\section{Introduction}

At present, carbon fiber (CF) is used as a type of reinforcement in various applications such as automobiles, aerospace, electronics and processing industries due to its high specific mechanical properties. ${ }^{1-6}$ The properties of both $\mathrm{CF}$ and a matrix as well as the interface between them act as a performance-determining factor of the composite material. A high degree of interfacial adhesion leads to better structural integrity of the composite material and effective load transfer between the fiber and polymer matrix. Carbon fiber-reinforced polymer composites show significant improvement in mechanical properties, however, their performance can be suppressed by the dominating properties of the polymer matrix. Incorporation of a reinforcing filler such as multiwalled carbon nanotubes (MWCNTs) with good mechanical properties into a CFreinforced composite can form a network that connects the higher polymer matrix region, and ultimately results in

Physics and Engineering of Carbon, CSIR-National Physical Laboratory, New Delhi-110012, India. E-mail: bps@nplindia.org; bpsingh2k4@yahoo.com; Fax: +9111-45609310; Tel: +91-11-45608460

$\dagger$ Electronic supplementary information (ESI) available. See DOI: $10.1039 / \mathrm{c} 6 \mathrm{ra} 08487 \mathrm{~g}$ improved mechanical properties. ${ }^{7}$ However, few researchers have reported that the nano-reinforcement effect is different depending on the degradation mechanism and reinforcement strategy, which should be customized based upon the design of the structure as well as the reinforcement loading. ${ }^{8}$

In composite materials, stress transfer between the reinforcement and matrix polymer mainly depends upon their interface, because weak interaction between $\mathrm{CF}$ and the PC matrix causes weak interfacial adhesion between them. To address these kinds of problems, various researchers supported the idea of incorporation of nanostructures into the polymer matrix., ${ }^{9,10}$ They suggested that it will improve the properties of composite materials because of increased interfacial adhesion due to the high specific area of nanostructures. For nanostructures, CNTs are considered as the most promising candidate to reinforce the matrix-rich region due to their high aspect ratio, nanoscale diameter and superior mechanical and electrical properties that provide widespread applications that alone CF cannot provide. Therefore, in recent times the incorporation of CNTs along with CF reinforcement into a polymer matrix has gained much attention. The incorporation of CNTs benefits the fiber-dominating properties to some extent, but the real benefit is expected in the matrix-dominating properties. 
These micro-nanohybrid composite materials create the possibility of fabricating light-weight multifunctional materials with enhanced mechanical and electrical properties that fulfil the requirement of modern society.

The reason behind the preparation of hybrid composites is to alter the properties in order to compensate the shortcoming of one factor by incorporating the other and meet the desired requirements. ${ }^{11-14}$ Dispersion of CNTs into a matrix plays a key role to fully gain the unique properties of CNTs in composite materials..$^{15}$ The incorporation of nano-sized CNTs along with a conventional micro-sized CF filler into the polymer matrix can be attained by two methods: (i) by direct incorporation into the polymer matrix ${ }^{16,17}$ or (ii) by carbon fiber utilizing CNTs. ${ }^{18-22}$ Altering the polymer matrix by dispersing MWCNTs via the direct incorporation method has several advantages over CF using MWCNTs such as low cost, high stability, ease of processing, and industrial viability. In the direct incorporation method, the $\mathrm{CF} /$ polymer composite is generally prepared by homogeneous dispersion of the filler by utilizing varied techniques, i.e. solvent casting and melt mixing. ${ }^{23}$

In recent years, because of their low density, high strength and modulus, CF-reinforced thermoplastic polymer composites have gained much attention. ${ }^{24-26}$ They offer various advantages over thermosetting polymers such as higher recyclability, environmental friendliness, and industrial viability as well as high damage tolerance. ${ }^{27}$ Polycarbonate (PC) is an engineering thermoplastic polymer with high mechanical properties and processability. Therefore, much attention has been given towards the development of high-performance thermoplastic composite materials using $\mathrm{PC}^{28}$ and polyphenyl sulfide (PPS) ${ }^{29}$ polymer matrices.

Currently, we are focusing on the former literature of experimental studies reported for various thermoplastic polymer composite materials. Only a handful of research has been done that discusses the mechanical properties of hybrid micronanocomposites. They reported an enhancement in the mechanical properties of composites along with the reinforcement content. Previous studies indicate that properties of composite materials largely depend upon the dispersion, surface modification, and alignment of fillers as well as their interaction with the polymer matrix. ${ }^{15,30-32}$ Ameli et al. synthesized both solid and foamed polypropylene/carbon fiber (PP$\mathrm{CF})$ composite materials using injection moulding. ${ }^{33}$ They reported that a foamed composite has better mechanical properties as compared to a solid composite. Hong et al. studied the carbon fiber-reinforced polypropylene composites in the presence of MWCNTs at different mixing speeds. ${ }^{34}$ They reported that a high mixing speed causes maximum dispersion of CF which improves the composite properties. Rahmanian et al. grew uniform CNTs on the surface of CF and glass fiber via the CVD method and prepared a composite with polypropylene polymer. ${ }^{35}$ They showed an increment in the tensile properties of these composites as compared to the neat short fiber composites because of the enhanced interaction between the fiber and matrix. Puch et al. investigated both the tensile and morphological properties of short CF-reinforced Nylon 6/ MWCNT composites. ${ }^{36}$ They showed an increment in these properties with an increment in the total filler content. They reported the dominating behavior of the CF filler for a greater CNT content.

The static and dynamic mechanical properties of CNT polymer composites depend on the concentration of the CNTs, surface modification, adhesion, and processing technique. Herein, we report the effect of functionalization of CNTs on the static and dynamic mechanical properties of $\mathrm{CF} / \mathrm{PC}$ composites to investigate the synergistic effect of the hybrid filler on the performance of PC. Prior to this study, no study has reported the effect of direct incorporation of carbon fiber along with functionalized (aMWCNTs) or non-functionalized (MWCNTs) carbon nanotubes into a PC polymer matrix via the melt mixing technique to the best of our knowledge. Static mechanical properties in the form of the tensile strength, Young's modulus, stress-strain behavior, flexural strength, flexural modulus and dynamic mechanical properties in the form of the storage modulus, loss modulus, $\tan \delta$, and stiffness are studied and analyzed. The degree of entanglement, $C$ factor and adhesion factor are evaluated to correlate the efficiency of reinforcement in the composites.

\section{Experimental}

\section{Materials}

In this work, thermoplastic polymer polycarbonate (Bayer Material Science, MAKROLON® 2407) was employed as a polymer matrix. This polymer grade had a softening point around $130-160^{\circ} \mathrm{C}$. The PAN-based carbon fiber (Toray T300) was used as reinforcement. The carbon fiber reinforcement had an average filament diameter of $7 \mu \mathrm{m}$. MWCNTs were synthesized via the chemical vapour deposition (CVD) technique, in which toluene is thermally decomposed in a constant heating zone of a quartz reactor in the presence of Fe catalyst, obtained from ferrocene. All the parameters regarding the MWCNT synthesis are given elsewhere. ${ }^{20}$ Functionalization of MWCNTs was done by refluxing MWCNTs in nitric acid for $24 \mathrm{~h}$ and these are labelled as aMWCNT. ${ }^{37,38}$

\section{Preparation of $\mathbf{C F} /$ polycarbonate composites}

Due to the several advantages of melt mixing over other methods, hybrid micro-nanocomposite specimens were prepared using a HAAKE MiniLab II Micro Compounder followed by a mini injector for injection moulding. Polycarbonate granules were pre-dried at $100{ }^{\circ} \mathrm{C}$ for 24 hours to remove the moisture trap. The PAN-based carbon fibers were cut to an average length of $0.5 \mathrm{~mm}$ using a fiber cutter. Former studies suggested that the high temperature and shear stress applied by the rotating screws can lead to a homogeneous distribution of reinforcement into the matrix on the expense of defected fillers. For that reason a melting temperature of $250{ }^{\circ} \mathrm{C}$ in the extruder and $290{ }^{\circ} \mathrm{C}$ for the injection cylinder along with a screw rotation of $100 \mathrm{rpm}$ was preferred over all others. All other optimized parameters related to the composite fabrication are elaborated elsewhere..$^{28,39}$ 
In this study, two types of moulds were used in injection moulding in order to examine the effect of different compositions of CF and MWCNT loading on the composite properties (Table 1). According to the standards the moulds used were: (i) tensile mould (ASTM D638), and (ii) flexural mould (ASTM D790). Flexural specimens were cut into dimensions of $12.5 \mathrm{~mm}$ $\times 6.3 \mathrm{~mm} \times 3.3 \mathrm{~mm}$ (length $\times$ width $\times$ thickness) in order to analyze the dynamic mechanical properties of the composite materials. These flexural samples were cut using a diamond cutter machine. The whole process for the hybrid micronanocomposite fabrication is shown in Fig. 1.

\section{Characterization}

Morphological characterization. Optical microscopy was utilized in order to examine the morphological properties of both the flexural and tensile composite specimens. These studies were done using a Zeiss Axiolab A1 instrument, operated at magnification of $10 \times$ and $100 \times$.

\section{Mechanical properties measurement}

Tensile and flexural measurements. The mechanical properties of both flexural (ASTM D790) and dog bone-shaped (ASTM

Table 1 Composite sample prepared using injection moulding

\begin{tabular}{|c|c|c|c|c|}
\hline Composite & Code & PC (wt\%) & MWCNT/aMWCNT (wt\%) & $\mathrm{CF}(\mathrm{wt} \%)$ \\
\hline Pure PC & Pure & 100 & - & - \\
\hline $2 \mathrm{wt} \% \mathrm{MWCNT} / \mathrm{PC}$ & PC2CNT & 98 & 2 & - \\
\hline 2 wt\% aMWCNT/PC & PC2aCNT & 98 & 2 & - \\
\hline $2 \mathrm{wt} \% \mathrm{CF} / \mathrm{PC}$ & $\mathrm{PC} 2 \mathrm{CF}$ & 98 & - & 2 \\
\hline 1 wt\% CF/1 wt\% MWCNT/PC & PC1CF1CNT & 98 & 1 & 1 \\
\hline $1 \mathrm{wt} \% \mathrm{CF} / 1 \mathrm{wt} \%$ aMWCNT/PC & PC1CF1aCNT & 98 & 1 & 1 \\
\hline $5 \mathrm{wt} \% \mathrm{CF} / \mathrm{PC}$ & PC5CF & 95 & - & 5 \\
\hline $10 \mathrm{wt} \% \mathrm{CF} / \mathrm{PC}$ & PC10CF & 90 & - & 10 \\
\hline $15 \mathrm{wt} \% \mathrm{CF} / \mathrm{PC}$ & PC15CF & 85 & - & 15 \\
\hline $20 \mathrm{wt} \% \mathrm{CF} / \mathrm{PC}$ & PC20CF & 80 & - & 20 \\
\hline 18 wt $\%$ CF $/ 2$ wt $\%$ MWCNT/PC & PC18CF2CNT & 80 & 2 & 18 \\
\hline 18 wt\% CF/2 wt\% aMWCNT/PC & PC18CF2aCNT & 80 & 2 & 18 \\
\hline
\end{tabular}

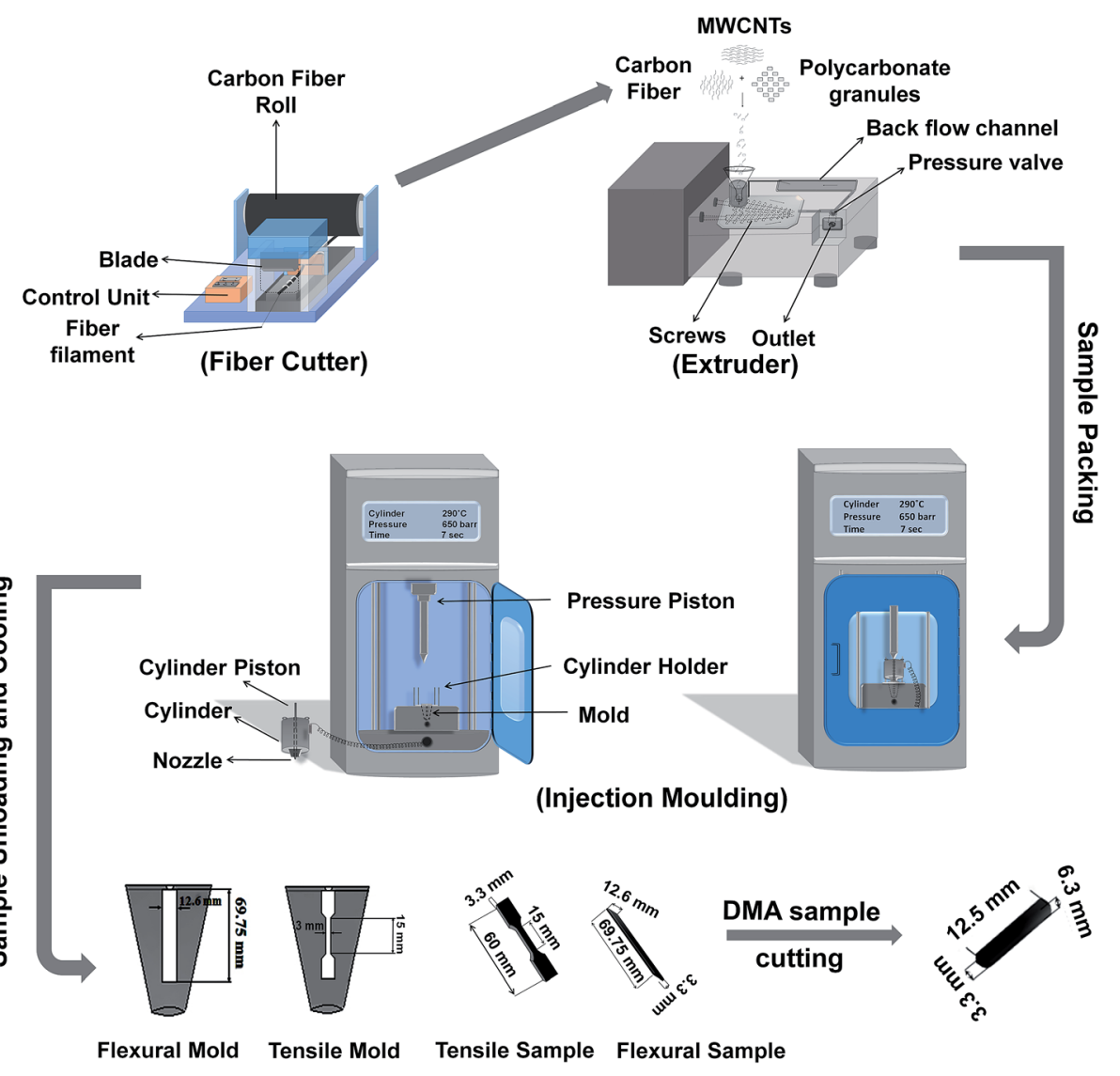

Fig. 1 Schematic diagram for the fabrication of hybrid micro-nanocomposite specimens using extrusion followed by injection moulding. 
D638) composites having different compositions were analyzed by an Instron universal testing machine (model 4411). The flexural specimen had dimensions of $69.75 \mathrm{~mm} \times 12.6 \mathrm{~mm} \times$ $3.3 \mathrm{~mm}$ (length $\times$ width $\times$ thickness) while the tensile specimens had dimensions in the order of $15.00 \mathrm{~mm} \times 3.00 \mathrm{~mm} \times$ $3.3 \mathrm{~mm}$ (length $\times$ width $\times$ thickness) along with a total length of $60 \mathrm{~mm}$. For the flexural and tensile specimens, the span length and gauge length values were $15 \mathrm{~mm}$ and $50 \mathrm{~mm}$, respectively, while the cross-head speed remained at $1 \mathrm{~mm}$ $\min ^{-1}$.

Dynamic mechanical thermal analysis (DMTA). The dynamic properties of the composite specimens were evaluated utilizing a dynamic mechanical analyzer (Perkin Elmer DMA 8000 Instrument). The single cantilever clamp was used at a vibrational frequency of $1 \mathrm{~Hz}$ in order to test the composite specimens in the temperature range of 40 to $180{ }^{\circ} \mathrm{C}$ with a scanning rate of $2{ }^{\circ} \mathrm{C} \min ^{-1}$. The testing specimens had the dimensions of $12.5 \mathrm{~mm} \times 6.3 \mathrm{~mm} \times 3.3 \mathrm{~mm}$ (length $\times$ width $\times$ thickness) . The storage modulus, loss modulus and $\tan \delta$ were calculated utilizing the formulae: ${ }^{39,40}$

$$
\begin{gathered}
\text { Storage modulus }\left(E^{\prime}\right)=G^{\prime} / \gamma \\
\text { Loss modulus }\left(E^{\prime \prime}\right)=G^{\prime \prime} / \gamma \\
\tan \delta=E^{\prime \prime} / E^{\prime}
\end{gathered}
$$

where $\gamma$ is the sinusoidal strain, and $G^{\prime}$ and $G^{\prime \prime}$ are the amplitude of the in-phase and out-of-phase stress components, respectively.

Raman spectroscopy. Raman characterization of the composite specimens was carried out in the range 100-3000 $\mathrm{cm}^{-1}$ using an excitation laser source of $785 \mathrm{~nm}$ wavelength in a Renishaw inVia Raman spectrometer, UK. The power of the laser source was $5 \mathrm{~mW}$ with $10 \mathrm{~s}$ of exposure time.

\section{Results and discussion}

\section{Mechanical properties}

In this work, the effect of various combinations of reinforcement, i.e. functionalized, non-functionalized MWCNTs and chopped CFs, has been studied for both the static and dynamic mechanical properties of composite materials. The amount of CF loading is restrained up to $20 \mathrm{wt} \%$, and the properties of these specimens are compared with those of hybrid micronanocomposites containing an equal amount of filler content including a small amount of MWCNTs ( 2 wt\% CNTs). The reason behind the incorporation of this specific amount of MWCNTs ( $2 \mathrm{wt} \%$ ) is the uniform dispersion at this concentration, which has already been revealed in our previous work. ${ }^{28,39}$

\section{Tensile properties of PC composite samples}

The stress-strain curve for the varied composition of PC composites is shown in Fig. 2. As observed in Fig. 2(a), incorporation of $\mathrm{CF}$ leads to a decay in the elongation at break as compared to the pure PC polymer which indicates the brittle behavior of $\mathrm{CF} / \mathrm{PC}$ composites. The composite samples break just after reaching the yielding point, which is an indicator of the brittle fracture behavior of composite materials (Fig. 2(a)). On the other hand, ductile behavior is noticed for both $2 \mathrm{wt} \%$ MWCNT and aMWCNT/PC nanocomposites (Fig. 2(c)). The aMWCNTs display a higher degree of ductility because of the presence of functionalized groups present on the MWCNT surface that cause higher interaction with the polymer matrix. The presence of small amounts of MWCNTs or aMWCNTs in the CF/PC hybrid nanocomposites causes a small increase in the ductile behavior as well as enhancing the strain value of the hybrid nanocomposites, which is shown in Fig. 2(c) and (d), respectively. All of this is also evident from the actually failed composite samples shown in Fig. 2(e) and (f). The point of fracture for the samples moves toward the edge of the neck along with the CF concentration that supports the deduction of improvement in the brittleness of the composite materials with respect to the $\mathrm{CF}$ amount.

The role of fillers can be identified by comparing stress values of various composite materials. As seen from Fig. 2(c) and (d), strain values (above and below the yielding point) show higher stress values for composite materials with increased filler loading, below their elongation at break. The hybrid micronanocomposites show both higher stress and strain values. This type of evaluation is necessary for applications requiring the identification of a composite material with a higher stiffness that does not undergo yielding beyond a specified level along with maintaining higher strength properties. ${ }^{41}$

The role of reinforcement on both the elastic modulus and ultimate tensile strength (UTS) properties of composite materials is shown in Fig. 3. From Fig. 3(a), it is evident that the UTS of lone CF-reinforced composite samples increases along with $\mathrm{CF}$ incorporation and reaches up to $91.3 \mathrm{MPa}$ for PC20CF, which is $37.3 \%$ higher than that of pure PC (66.5 MPa). As for the CNT/ CF-reinforced hybrid nanocomposites, the UTS increases by 40.75\% (93.6 MPa) for PC18CF2aCNT and 39.2\% (92.6 MPa) for the PC18CF2CNT composite with respect to the pure PC (66.5 $\mathrm{MPa}$ ) (Fig. 3(c)). The increase in the UTS with CNT amount in the CF/PC samples is indicative of the effective external load transfer between the fillers and the polymer matrix. Incorporation of both the CF and MWCNTs together causes a significant synergistic effect on the mechanical properties of the polycarbonate composite. The combined influence of reinforcements for the tensile and flexural modulus as well as strength is considerably larger as compared to their individual contribution in a composite material incorporated with lone CF and MWCNTs. During a MWCNT-related failure event, the stress transfer process done by MWCNTs is followed by void propagation, thus reducing the stress concentration on $\mathrm{CF}$ fillers.

Similar patterns of increment are seen in the elastic modulus for the CF/PC composite materials (Fig. 3(b)). Incorporation of MWCNT/aMWCNTs in the CF/PC composite causes further enhancement in the elastic modulus. The average increment in the elastic modulus for the PC20CF composite is 132.2\% (3149 $\mathrm{MPa}$ ), 143.7\% (3304 MPa) for PC18CF2aCNT, and 137.4\% (3219 $\mathrm{MPa}$ ) for the PC18CF2CNT composite as comparison to pure PC (1356 MPa) (Fig. 3(b)). 

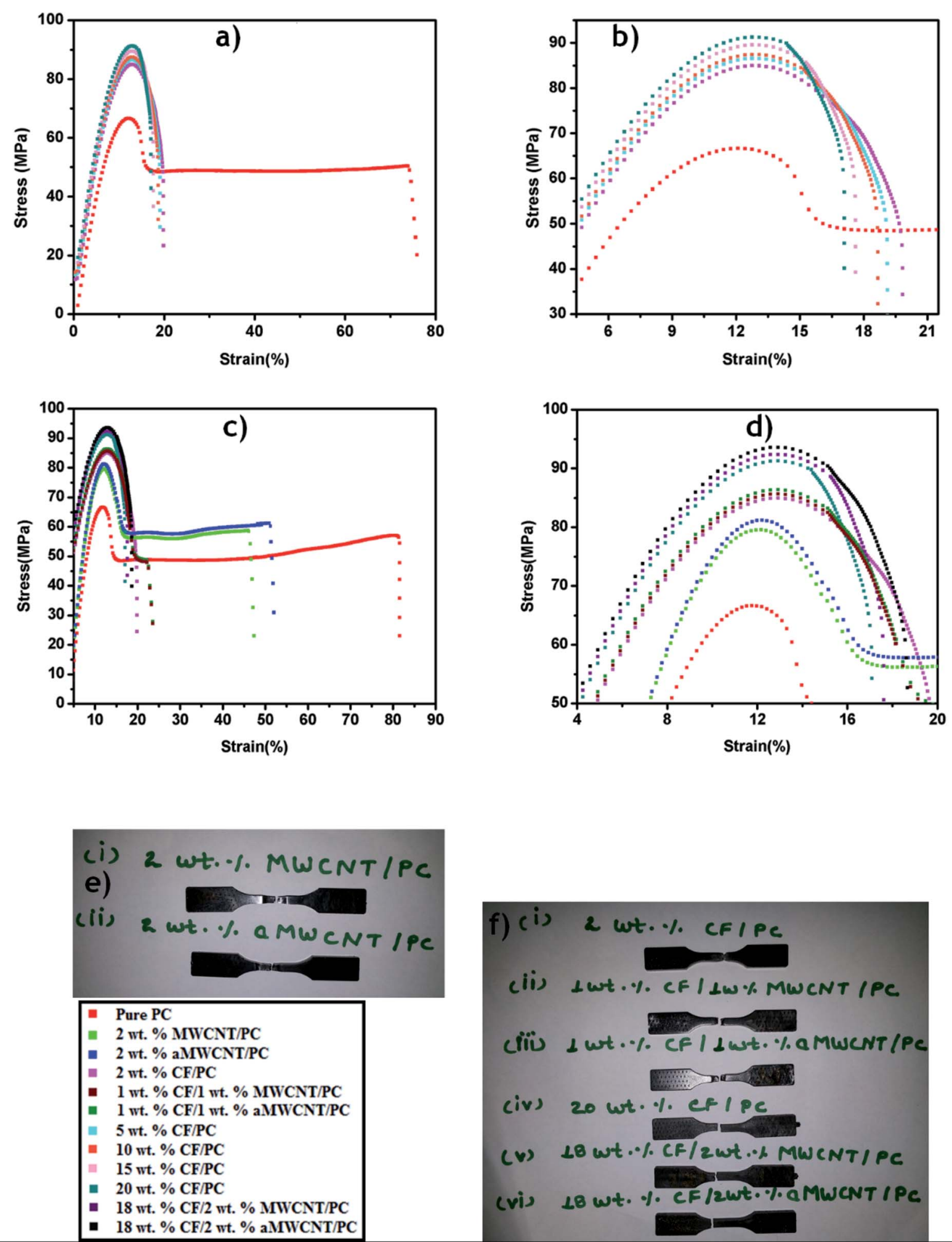

Fig. 2 Tensile stress-strain curves of (a) CF/PC composites, (b) zoomed in on the stress-strain curve, (c) hybrid micro-nanocomposites (CF/ CNT/PC), and (d) zoomed in on the stress-strain curve, (e) and (f) fracture behavior of failed composite specimens.

By observing different CF/CNT/PC hybrid composites, it can be deduced that incorporation of small amounts of CNTs in various samples leads to higher filler-filler as well as filler- matrix interaction that causes further enhancement in both the UTS and elastic modulus value of the composite samples. All the tensile property parameters are stated in Table S1 (ESI $†$ ). 

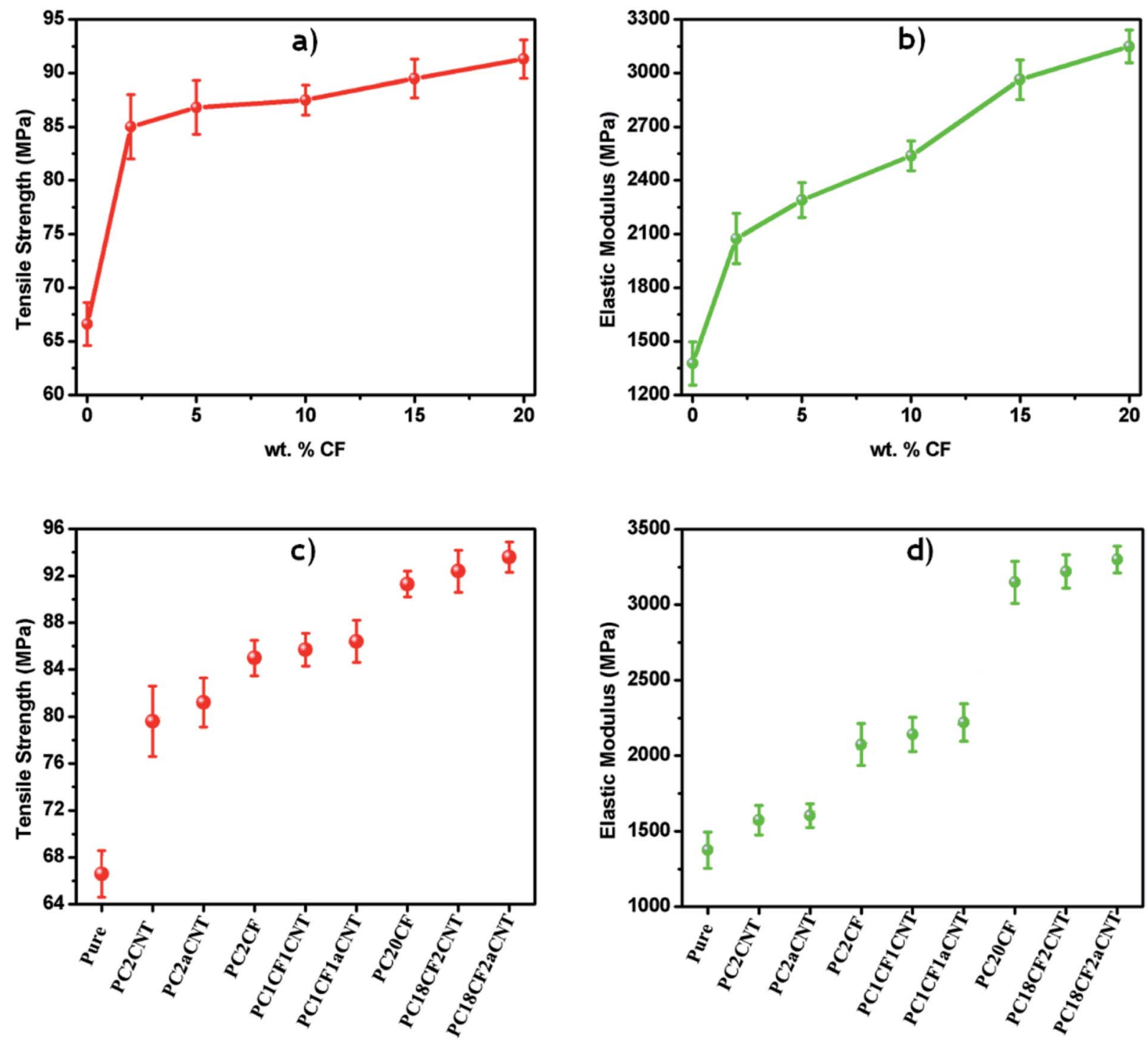

Fig. 3 Effect of filler loading on tensile properties for various microcomposites: (a) tensile strength and (b) elastic modulus, and for various hybrid micro-nanocomposites: (c) tensile strength and (d) elastic modulus.

\section{Flexural properties of $\mathrm{CF} / \mathrm{PC}$ composite samples}

In the flexural test, a higher loading of CF reinforcement led to a fracture of the composite samples without plastic deformation. The effect of the reinforcement filler on the flexural properties is shown in Fig. 4. It is clear from Fig. 4(a) and (b) that both the flexural modulus and strength show a significant improvement with a lone CF loading up to $134 \mathrm{MPa}$ for PC20CF, which is $39.9 \%$ higher than that for the pure PC matrix (95.8 $\mathrm{MPa}$ ). Incorporation of $2 \mathrm{wt} \%$ MWCNTs in CF/PC materials enhances the flexural properties (Fig. 4(c) and (d)) such as the flexural strength of the PC18CF2aCNT and PC18CF2CNT samples, which shows a $42.6 \%$ and $41.3 \%$ increment, respectively, over pure PC.

Beside this, an improvement in the average flexural modulus is $128.4 \%$ ( $4920 \mathrm{MPa}$ ) for PC20CF with respect to the pure PC polymer (2154 MPa). Incorporation of functionalized and nonfunctionalized MWCNTs in micro CF/PC composite material leads to a $142.94 \%$ and $136.70 \%$ enhancement over neat PC, respectively. All the flexural property parameters are stated in Table S1 (ESI†).

\section{Dynamic mechanical properties}

Dynamic mechanical analysis is a versatile technique, which is used to obtain results for a wide range of parameters that are related to the mechanical properties of the material. In this investigation $\tan \delta$, stiffness, and the storage and loss modulus are investigated for the viscoelastic polymer. All these parameters are measured at three different regions: the glassy region, transition zone and rubbery region. A transition of the polymer material from the glassy to rubbery state is known as a transition zone.

The results from three-point bending are coherent with the storage modulus results for the micro, nano and hybrid micronanocomposites. The effect of various CF loadings on the 

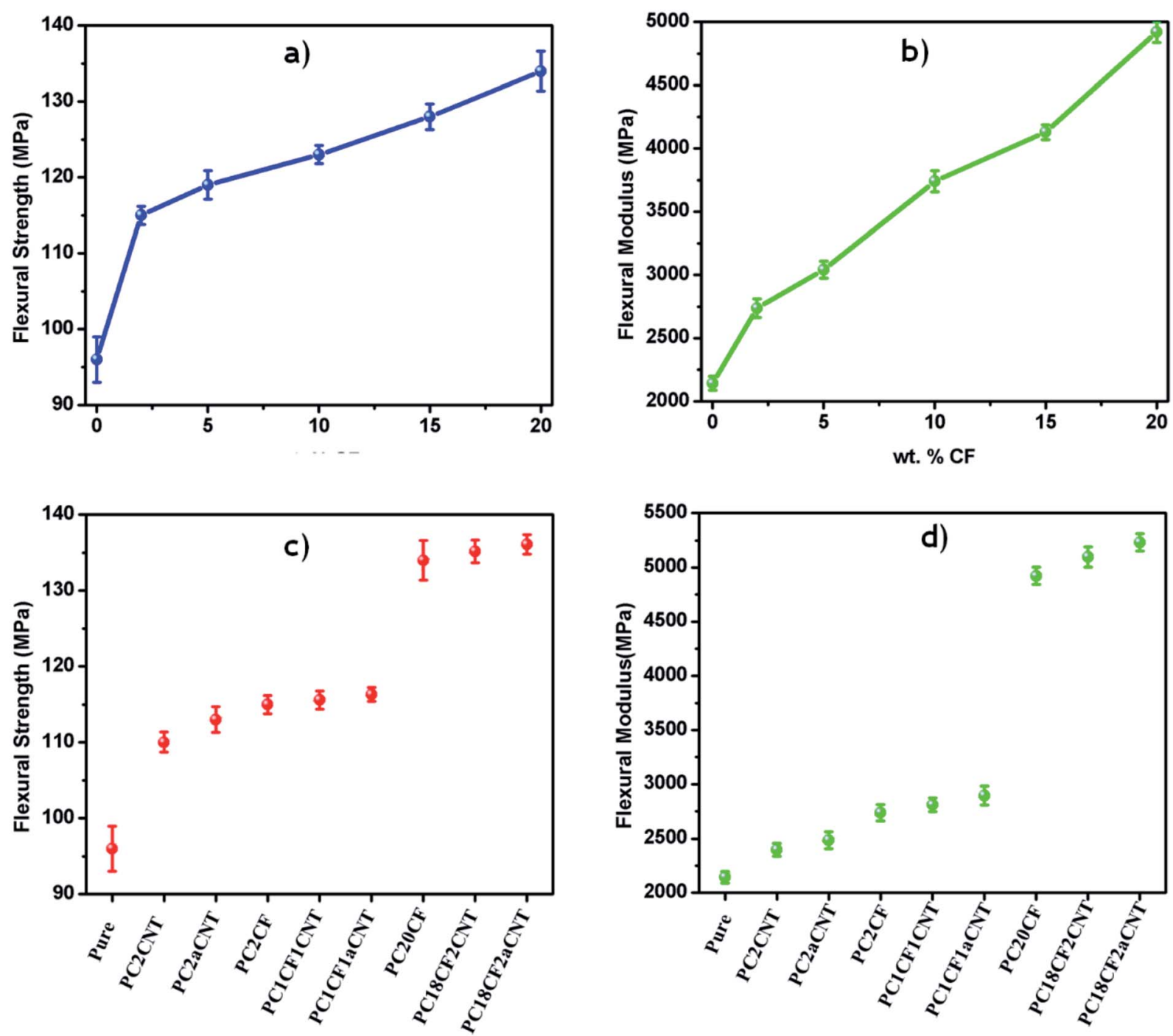

Fig. 4 Effect of different filler loading on flexural properties for various microcomposites: (a) flexural strength and (b) flexural modulus, and for various hybrid micro-nanocomposites: (c) flexural strength and (d) flexural modulus.

storage modulus of composite materials is shown in Fig. 5(a). From Fig. 5(a), it is obvious that the storage modulus continuously increases along with the increment in the CF content. In the glassy region, the composite samples show a trivial amount of alteration with respect to the temperature increment and maintain a plateau. This enhancement in $E^{\prime}$ for the PC20CF $(2904 \mathrm{MPa})$ and PC2CF $(1750 \mathrm{MPa})$ samples is $176.6 \%$ and $66.7 \%$, respectively, over the pure PC (1050 MPa) sample at 40 ${ }^{\circ} \mathrm{C}$ (Fig. 5(a)). As for the rubbery region (above $T_{\mathrm{g}}$ ), the improvements are $1200 \%$ and $366 \%$ for PC20CF (39 MPa) and PC2CF (14 MPa), respectively, compared to the pure PC (3 MPa) sample at $180{ }^{\circ} \mathrm{C}$. In addition to that, incorporation of a minor amount of MWCNTs and aMWCNTs causes further enhancement in the storage modulus value due to the filler-filler and filler-polymer interaction. The increment in $E^{\prime}$ is $189.5 \%$ (3040 $\mathrm{MPa}$ ) for the PC18CF2CNT sample and 203.3\% (3185 MPa) for PC18CF2aCNT as compared to that of pure PC at $40{ }^{\circ} \mathrm{C}$ (Fig. 5(b)). Samples PC18CF2CNT and PC18CF2aCNT show a $4.7 \%$ and $9.7 \%$ improvement in $E^{\prime}$ over the PC20CF sample.
This increment in $E^{\prime}$ is because of the even distribution of chopped CF as well as CNTs inside the PC matrix employed by applying appropriate shear stress during melt mixing that causes filler-polymer chain network formation, which acts as a reinforcement. Besides all of this, Fig. 5(a) and (b) also exhibit the disproportionate behavior between the modulus and temperature gradient which is attributed to the enhanced mobility of the polymer chains. Fig. 5(c) shows the increment in the loss modulus for a varied CF content. It is obvious that incorporation of reinforcement causes broadening as well as an increment in the loss modulus peak. One of the main reasons behind such a rise in the loss modulus is internal fraction that heightens the heat dissipation in the composite material. The decline in the loss modulus value after reaching its peak value is due to the free movement of chains present in the material.

The effectiveness of reinforcement on the matrix polymer can be evaluated by the coefficient $C$. It is a relative measurement of the decline in the modulus along with a temperature 

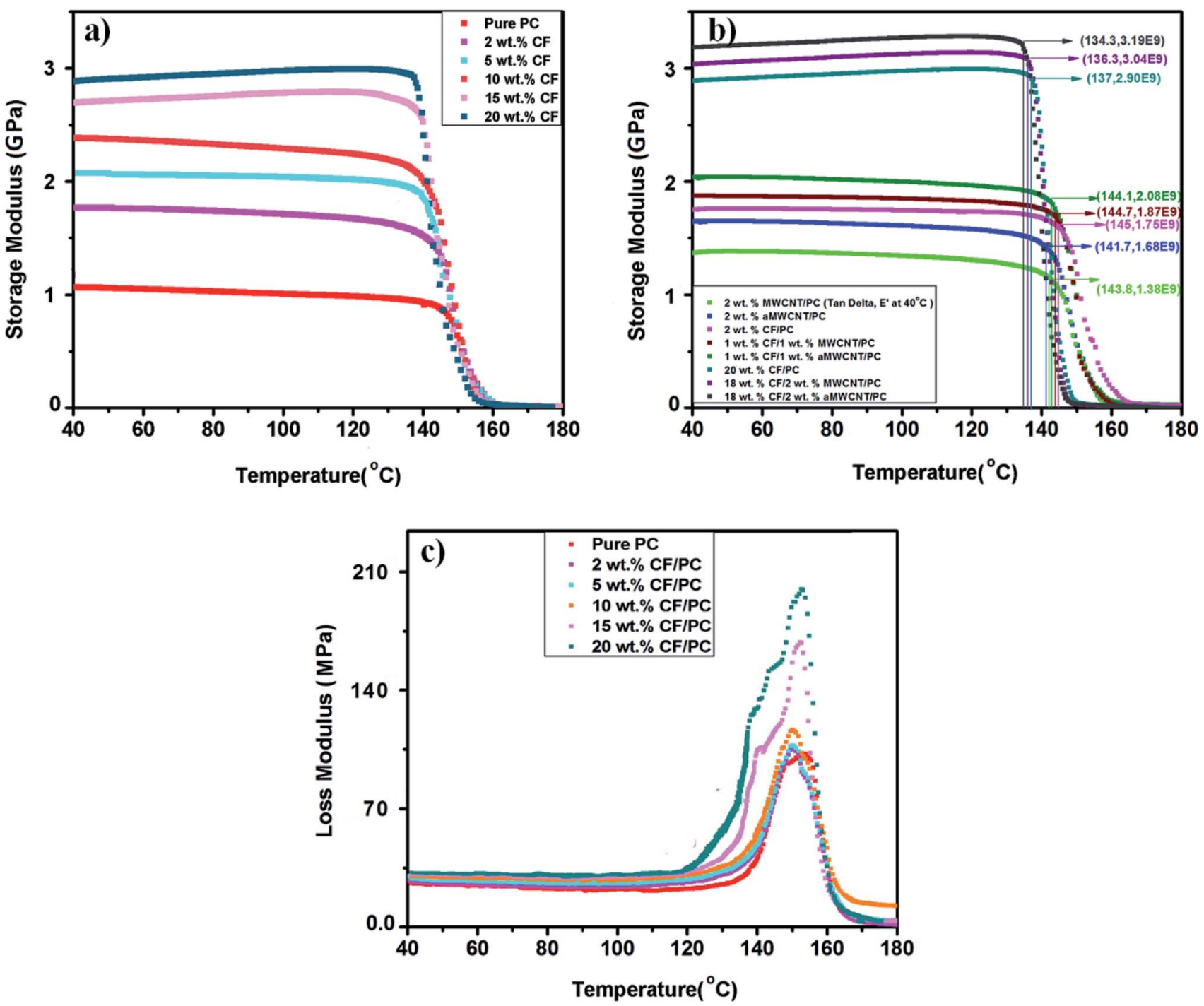

Fig. 5 Effect of filler loading on dynamic properties of composite specimens: (a) storage modulus of CF/PC composites, (b) storage modulus of CF/MWCNT/PC composites, and (c) loss modulus of CF/PC composites.

increment. The coefficient $C$ parameters are calculated using the formula: ${ }^{42,43}$

$$
C=\frac{\left(E_{\mathrm{g}}^{\prime} / E_{\mathrm{r}}^{\prime}\right)_{\text {composite }}}{\left(E_{\mathrm{g}}^{\prime} / E_{\mathrm{r}}^{\prime}\right)_{\text {pure }}}
$$

where $E_{\mathrm{g}}^{\prime}$ and $E_{\mathrm{r}}^{\prime}$ are the storage modulus values of the glassy and rubbery region respectively.

The value of the coefficient is inversely proportional to the reinforcement effectiveness. Fig. 6(a) exhibits the coefficient $C$ values for varied composite specimens at a frequency of $1 \mathrm{~Hz}$. It is apparent from the figures that incorporation of reinforcement leads to a continuous decline in the coefficient $C$ values. For a similar content of reinforcement, composite specimens containing a small amount of functionalized MWCNTs demonstrate a lower $C$ value than that of the as-synthesized MWCNTs, indicative of the higher effectiveness of aMWCNTcontaining composite specimens.
Alongside the effectiveness of reinforcement, the degree of entanglement also plays a key role in providing composite materials their specific properties. The degree of entanglement between the matrix and filler can be evaluated by the following equation: ${ }^{\mathbf{4}}$

$$
N=E^{\prime} / 6 R T
$$

where $E^{\prime}$ is the storage modulus of the composite specimens, $R$ is the universal gas constant, and $T(\mathrm{~K})$ is the temperature. Fig. 6(b), (c) and (d) display the degree of entanglement values for different types of composite materials at $40{ }^{\circ} \mathrm{C}, 130{ }^{\circ} \mathrm{C}$ and $180{ }^{\circ} \mathrm{C}$, respectively. At those temperatures, the entanglement density increases uninterruptedly for a higher amount of filler content. A composite material with as-synthesized or functionalized MWCNTs shows a higher order of entanglement as compared to the other specimens resulting in enhanced mechanical properties, supporting previously obtained 

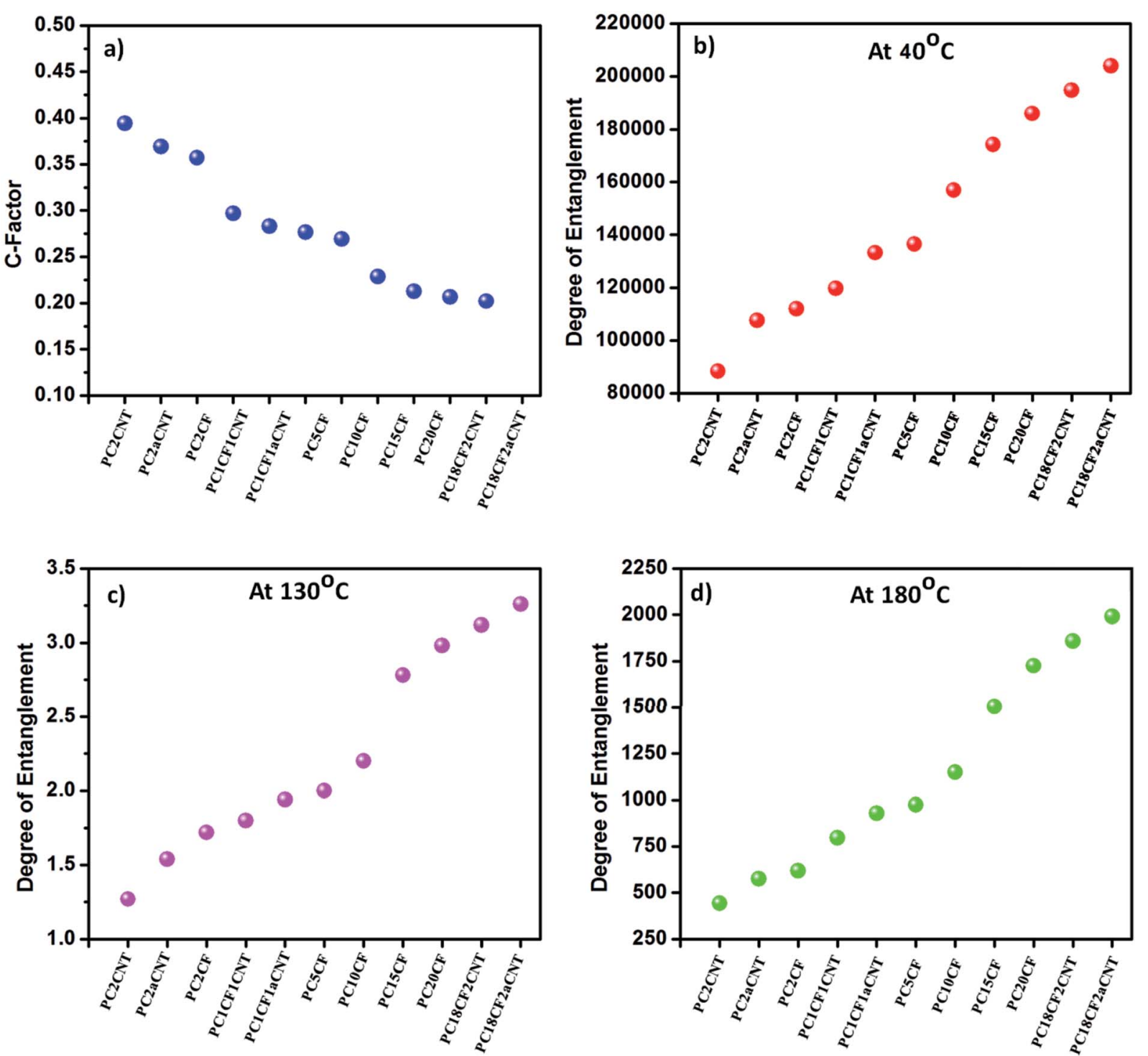

Fig. 6 Effect of reinforcement loading on (a) coefficient $C$ factor, (b) degree of entanglement at $40{ }^{\circ} \mathrm{C}$, (c) degree of entanglement at $130{ }^{\circ} \mathrm{C}$, and (d) degree of entanglement at $180^{\circ} \mathrm{C}$.

patterns. All the storage modulus and coefficient $C$ values along with the degree of entanglement parameters are stated in Tables S2 and S3, respectively (ESI $\dagger$ ).

The damping factor, $\tan \delta$, is a ratio of loss to storage modulus, which measures the amount of deformation energy in the form of heat, dissipated per cycle. The glass transition temperature $\left(T_{\mathrm{g}}\right)$ of the composite samples was studied by evaluating both $\tan \delta$ and the storage modulus values. The maximum value of $\tan \delta$ and swift decline in $E^{\prime}$ value in contrast to the temperature increment is considered as $T_{\mathrm{g}}$. Fig. 7 exhibits the value of $\tan \delta$ for different wt $\%$ of the micro-nanohybrid composites. The depression in $T_{\mathrm{g}}$ calculated from $\tan \delta$ is almost $4{ }^{\circ} \mathrm{C}$ for varied composite samples. The $T_{\mathrm{g}}$ values resulting from tan $\delta$ and $E^{\prime}$ values varied from 160.2 to $156.2^{\circ} \mathrm{C}$ and 145.3 to $134.3^{\circ} \mathrm{C}$ for the pure PC polymer to PC18CF2aCNT composite sample, respectively (Fig. 7). As observed from Fig. 7, the area under the $\tan \delta$ peak decreases with the increased amount of reinforcement. This decline suggests that the fraction of polymer confined by reinforcement increases with the filler content and only a small portion of the polymer is involved with the glass transition temperature.

The interaction between the reinforcement and polymer matrix is assessed by evaluating the adhesion factor which is determined from the tan $\delta$ value of the composite and pure PC as a function of the filler volume fraction. It can be expressed as: ${ }^{\mathbf{2}}$

$$
A=\frac{\tan \delta_{\mathrm{c}}}{\left(1-V_{\mathrm{f}}\right) \tan \delta_{\mathrm{p}}}-1
$$

where $V_{\mathrm{f}}, \tan \delta_{\mathrm{c}}$ and $\tan \delta_{\mathrm{p}}$ are the volume fraction of filler, and damping factor of the composite and pure PC polymer, respectively. The value of the adhesion factor is lower for a composite material with a high order of interaction between the filler and polymer matrix. The micro-nanohybrid composites demonstrate a higher degree of interaction between the 

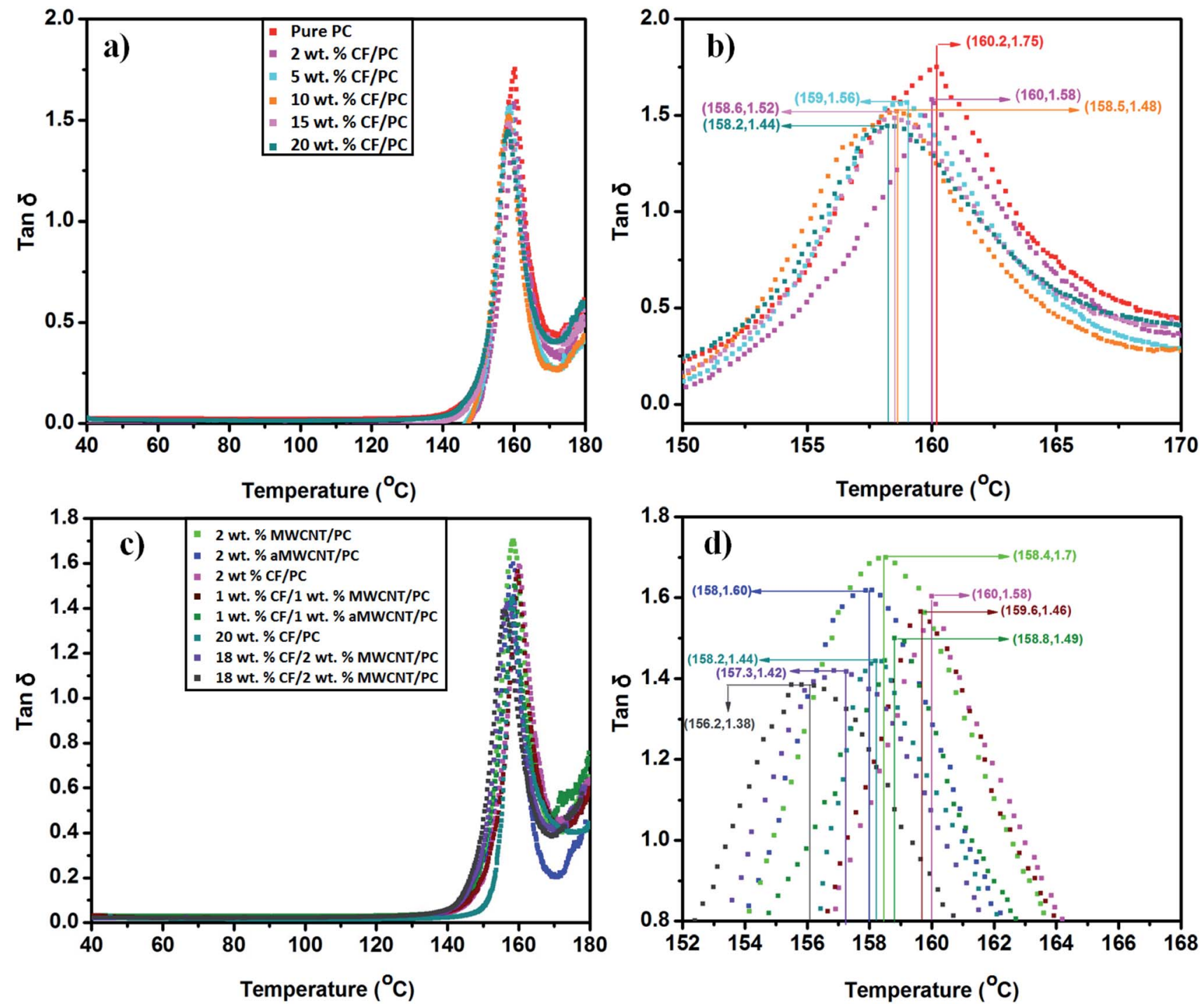

Fig. 7 Effect of fillers on dynamical mechanical properties of polycarbonate composites, CF/PC composites: (a) tan $\delta$, and (b) at a lower range of temperature scale (zoomed in), and CF/MWCNT/PC composites: (c) $\tan \delta$, and (d) at a lower range of temperature scale (zoomed in).
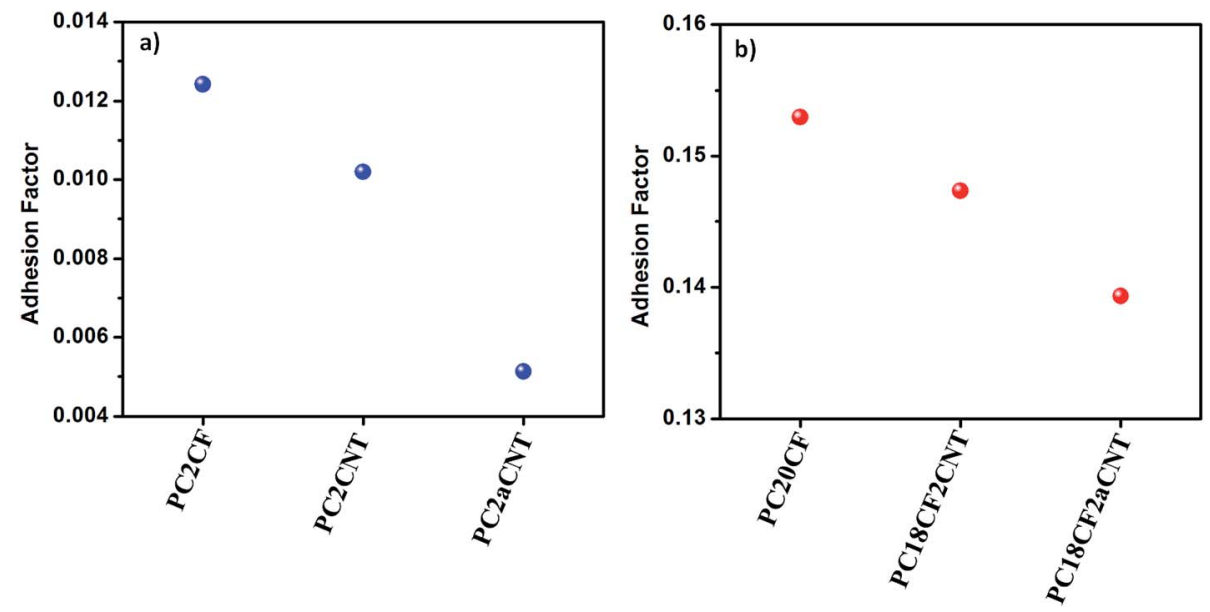

Fig. 8 Effect of different weight\% of filler loading on adhesion factor: (a) 2 weight\% and (b) 20 weight\%. 

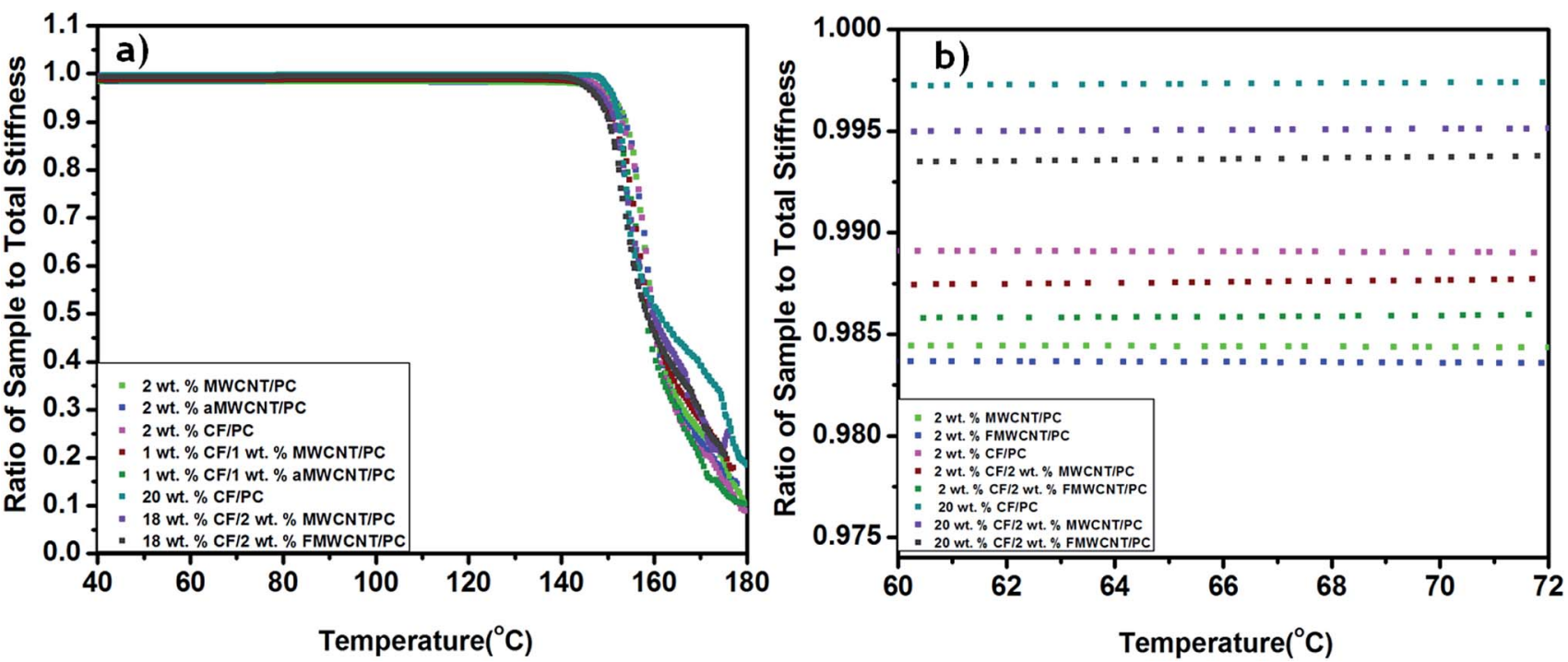

Fig. 9 Effect of CF/MWCNT incorporation on hybrid composite properties over a specific temperature range: (a) stiffness and (b) at a lower range of temperature scale (zoomed in).
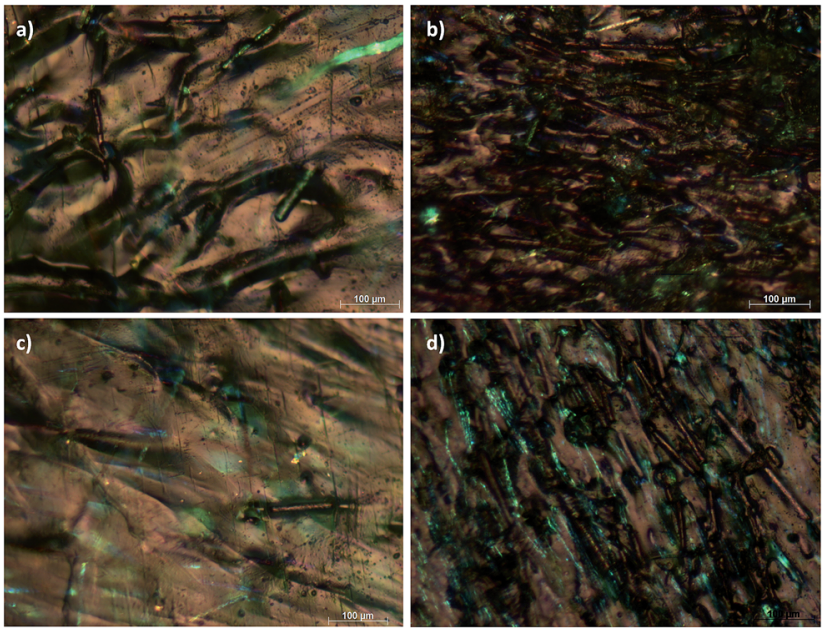

Fig. 10 Optical micrographs of flexural specimens: (a) 2 wt\% CF/PC composite and (b) $20 \mathrm{wt} \% \mathrm{CF} / \mathrm{PC}$ composite, and tensile specimens: (c) $2 \mathrm{wt} \%$ CF/PC composite and (d) $20 \mathrm{wt} \%$ CF/PC composite.

matrix and filler as compared to the microcomposites for an equal amount of filler content. From Fig. 8(a) and (b), it is obvious that composite specimens containing aMWCNTs have greater interactions with the polymer matrix in contrast to both the as-synthesized MWCNT and CF-containing specimens for an equal amount of filler. This evaluation is also in coherence with the flexural and tensile measurements. All the parameters regarding $T_{\mathrm{g}}$ and the adhesion factor are stated in Table S4 $(\mathrm{ESI} \dagger)$.

The effect of reinforcement on the stiffness of the composite material is shown in Fig. 9. The stiffness of the composite samples highly depends on the type of reinforcement. From Fig. 9(b), it can be concluded that the presence of nonfunctionalized CNTs shows a higher degree of stiffness as compared to the functionalized CNTs. CF microcomposites show higher stiffness than hybrid micro-nanocomposites for the same amount of filler content. All of this is also evident in the fracture pattern of the tensile composite samples (Fig. 2(e) and (f)).

\section{Optical microscopy}

The uniform distribution of reinforcement in the matrix polymer that is mandatory to fully gain the theoretical value of the filler, as well as the fracture behavior of the composite materials and how fillers contribute to minimize the strain effect, are all investigated utilizing an optical microscope. Formation of a)

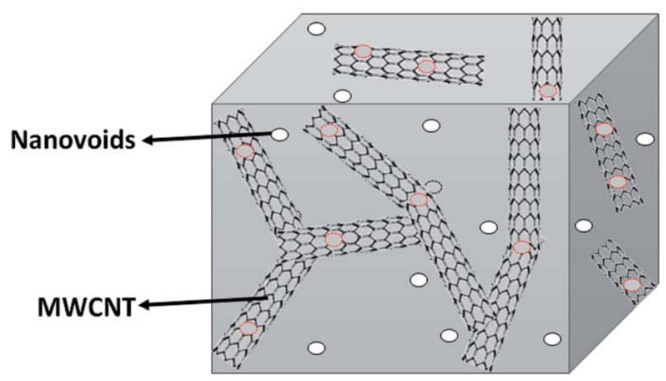

b)

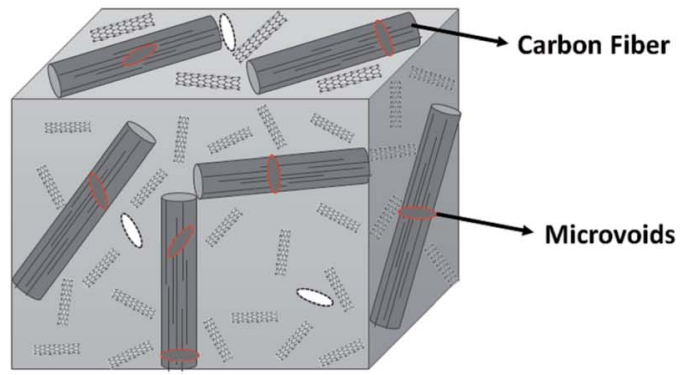

Fig. 11 Schematic representation of the role of fillers during stress conditions. 

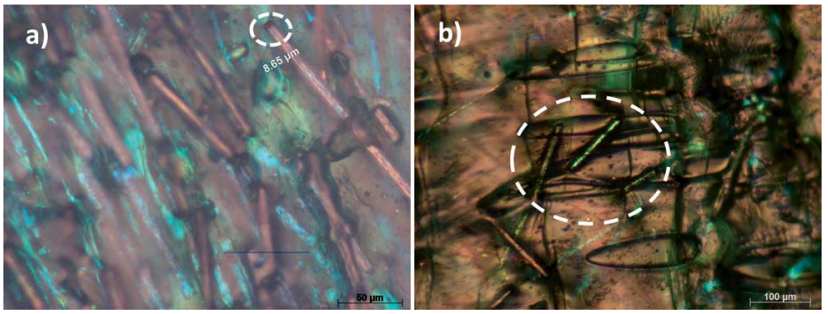

Fig. 12 (a) Evaluation of CF diameter in 20 wt\% CF/PC composite and (b) reinforcement effect of CF filler in the $2 \mathrm{wt} \% \mathrm{CF} / \mathrm{PC}$ tested specimen.

aggregates in a composite material can create defects that can deteriorate the properties of a composite sample. Both the flexural and tensile specimens are investigated in this study. Fig. 10(a) and (b) show the optical microscopy images of the 2 and $20 \mathrm{wt} \% \mathrm{CF} / \mathrm{PC}$ composite flexural specimens. It is apparent from the images that both specimens exhibit a higher dispersion of filler content, positively affecting the composite properties. A similar kind of pattern of dispersion can be observed in the tensile specimens with a slightly better alignment of CF reinforcement (Fig. 10(c) and (d)). This alignment is due to high pressure applied to the molten polymer in the neck during the sample packaging. These key points result in the superior mechanical properties of the composite specimens. All other optical images of various composite samples are shown in the ESI, Fig. S1. $\dagger$

Fig. 11 shows the role of reinforcement under applied stress conditions. Nanofillers such as MWCNTs act as a suppressor for the propagation of nanovoid formation due to the stress. After a certain high stress value, the MWCNTs cannot contain the nanovoids and they start to stretch to form microvoids (Fig. 11(a)). At the point of microvoid formation, the role of CNTs as a reinforcement starts to decline and the role of CF reinforcement is realized (Fig. 11(b)). Due to the diameter and interaction of $\mathrm{CF}$ embedded in the polymer on both sides of the microvoid, it tries to prevent further deterioration and reinstate the polymer to its former condition.

As seen in Fig. 12(a), the diameter of the CF calculated using a microscope is $8.65 \mu \mathrm{m}$ (marked with a dotted circle), which is much higher than the diameter of CF used in this study. This indicates the wetting effect of CF and supports the idea of the higher degree of interaction between $\mathrm{CF}$ and the PC polymer matrix. Fig. 12(b) shows the PC2CF specimen which was put
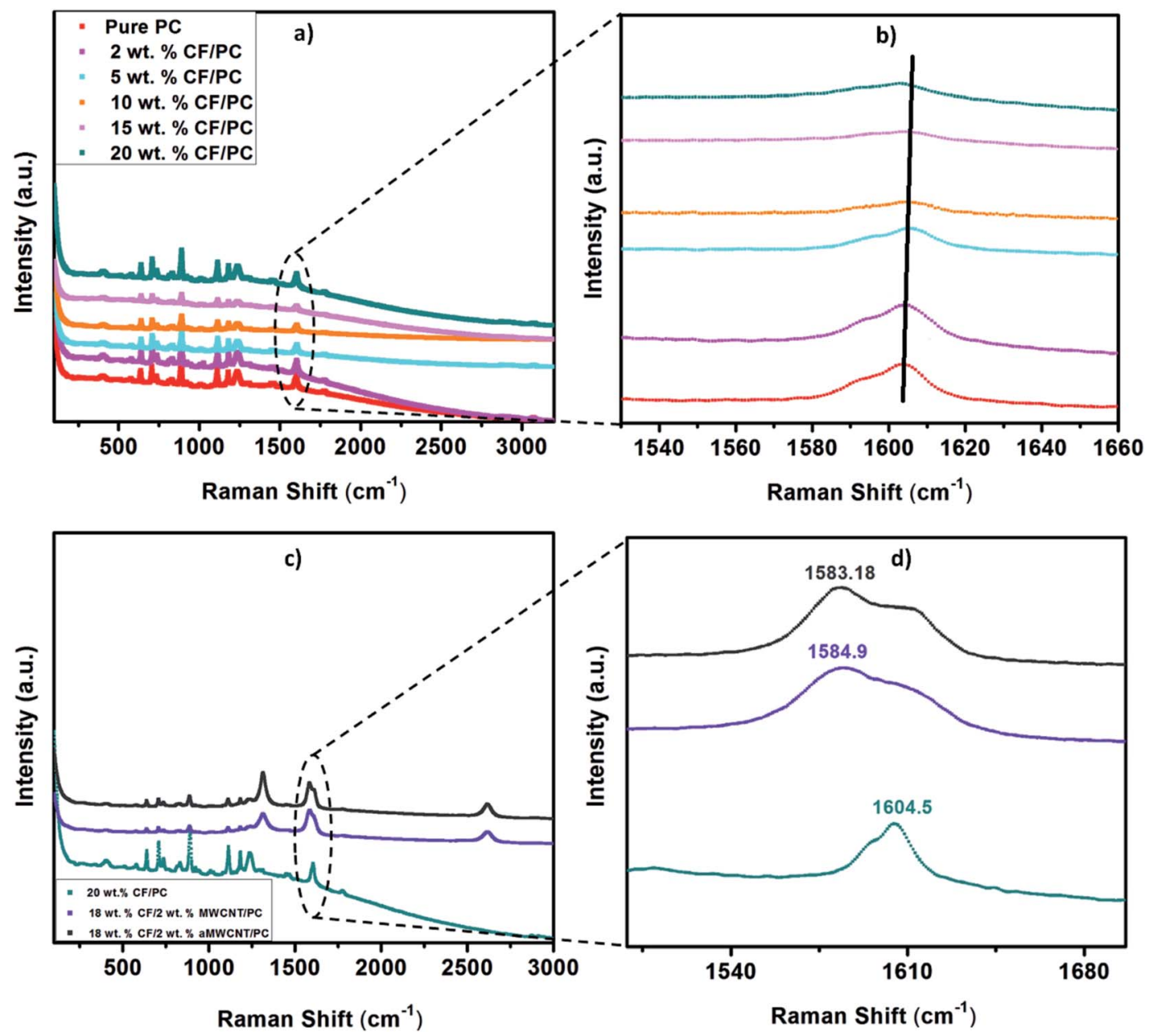

Fig. 13 Raman spectra of specimens: (a) CF/PC composites, (b) zoomed in on the shifting in the characteristic peak, (c) 20 wt\% filler content, and (d) zoomed in on the shifting in the characteristic peak. 
under high stress conditions, and gives evidence to support the above conclusion. It shows the stretching of the polymer matrix and formation as well as propagation of microvoids due to the applied stress. CF, marked with a dotted circle, has both ends embedded into the polymers and acts as a reinforcement against the void propagation and tries to reinstate the polymer to its previous geometry (Fig. 12(b)). This provides evidence for the high mechanical properties obtained for the composite samples.

\section{Raman spectroscopy}

Raman spectroscopy analysis of varied composite samples was carried out to examine the interaction between the reinforcement and PC matrix. Fig. 13 exhibits the Raman spectra of the carbon fiber-reinforced PC composites. It is evident from Fig. 13(a) and (b) that incorporation of the CF filler causes right side shifting in the characteristic peak of the PC polymer. This extent of shifting in the peak is related to the interaction between CF and the PC matrix. ${ }^{45,46}$ As for the hybrid micronanocomposites, the incorporation of a small amount of CNTs causes a high degree of wavelength shifting that is an indicative of higher interaction between the filler-filler and filler matrix. From Fig. 13(c) and (d), it is evident that functionalized CNTs reveal an even higher shifting in wavelength because of the much better interaction caused by the presence of functional groups on the surface.

By taking all of these observations into consideration, it can be proposed that the relation between shifting and interaction between the matrix and fillers is in good agreement with the results obtained from optical microscopy as well as tensile and flexural measurements.

\section{Conclusions}

Hybrid micro-nanocomposites were prepared using a twinscrew extruder followed by injecting moulding which allows uniform distribution of fillers such as MWCNTs and CFs into the matrix via applying proper shear force during mixing. Optical images of the composite specimens show a higher dispersion of CF fillers up to $20 \mathrm{wt} \%$ of CF content that leads to enhanced mechanical properties such as the flexural and tensile properties, as well as the storage modulus of the composite materials. This is also evident from the relation between the interaction between the filler and matrix composites and higher Raman shifting patterns of the composite specimens. Furthermore, a synergistic effect is observed by incorporating small amounts of MWCNTs along with CF reinforcement. These micro-nanohybrid composites have superior mechanical properties as compared to the composites reinforced by MWCNTs and CF alone, due to the greater interaction between the filler-filler and filler-matrix.

\section{Acknowledgements}

The authors are thankful to Mrs Shaveta Sharma for the mechanical properties measurement. The studies have been carried out under the CSIR-Network project (DNEED, PSC0109).

\section{References}

1 T. Zhang, C. H. J. Kim, Y. Cheng, Y. Ma, H. Zhang and J. Liu, Nanoscale, 2015, 7, 3285-3291.

2 L. Feng, K.-z. Li, Z.-s. Si, Q. Song, H.-j. Li, J.-h. Lu and L.-j. Guo, Mater. Sci. Eng., A, 2015, 626, 449-457.

3 P.-N. Wang, T.-H. Hsieh, C.-L. Chiang and M.-Y. Shen, J. Nanomater., 2015, 2015, 7.

4 J. Yang, C. Wang, K. Wang, Q. Zhang, F. Chen, R. Du and Q. Fu, Macromolecules, 2009, 42, 7016-7023.

5 Y. Jia, K. Li, L. Xue, J. Ren, S. Zhang and X. Zhang, Mater. Des., 2015, 86, 55-60.

6 S. R. Dhakate, A. Chaudhary, A. Gupta, A. Pathack, B. Singh, K. Subhedar and T. Yokozeki, RSC Adv., 2016, 6, 36715-36722.

7 F. Inam, D. W. Wong, M. Kuwata and T. Peijs, J. Nanomater., 2010, 2010, 9.

8 G. Lubineau and A. Rahaman, Carbon, 2012, 50, 2377-2395.

9 E. Thostenson, W. Li, D. Wang, Z. Ren and T. Chou, J. Appl. Phys., 2002, 91, 6034-6037.

10 E. Bekyarova, E. Thostenson, A. Yu, H. Kim, J. Gao, J. Tang, H. Hahn, T.-W. Chou, M. Itkis and R. Haddon, Langmuir, 2007, 23, 3970-3974.

11 A. Godara, L. Gorbatikh, G. Kalinka, A. Warrier, O. Rochez, L. Mezzo, F. Luizi, A. Van Vuure, S. Lomov and I. Verpoest, Compos. Sci. Technol., 2010, 70, 1346-1352.

12 S. Aziz, S. A. Rashid, S. Rahmanian and M. A. Salleh, Polym. Compos, 2015, 36, 1941-1950.

13 R. Sager, P. Klein, D. Lagoudas, Q. Zhang, J. Liu, L. Dai and J. Baur, Compos. Sci. Technol., 2009, 69, 898-904.

14 B. Schrauwen, P. Bertens and T. Peijs, Polym. Polym. Compos., 2002, 10, 259-272.

15 Z. Wang, P. Ciselli and T. Peijs, Nanotechnology, 2007, 18, 455709.

16 A. Isayev, R. Kumar and T. M. Lewis, Polymer, 2009, 50, 250260.

17 M. Moniruzzaman, F. Du, N. Romero and K. I. Winey, Polymer, 2006, 47, 293-298.

18 T. Yokozeki, Y. Iwahori, S. Ishiwata and K. Enomoto, Composites, Part A, 2007, 38, 2121-2130.

19 B. P. Singh, P. Bharadwaj, V. Choudhary and R. B. Mathur, Appl. Nanosci., 2014, 4, 421-428.

20 R. B. Mathur, S. Chatterjee and B. P. Singh, Compos. Sci. Technol., 2008, 68, 1608-1615.

21 R. B. Mathur, B. P. Singh, P. K. Tiwari, T. K. Gupta and V. Choudhary, Int. J. Nanotechnol., 2012, 9, 1040-1049.

22 B. P. Singh, V. Choudhary, P. Saini and R. B. Mathur, AIP Adv., 2012, 2, 022151.

23 R. Santos, C. Vilaverde, E. Cunha, M. Paiva and J. Covas, Soft Matter, 2016, 12, 77-86.

24 R. Stewart, Reinf. Plast., 2012, 56, 18-25.

25 W.-H. Liao, H.-W. Tien, S.-T. Hsiao, S.-M. Li, Y.-S. Wang, Y.-L. Huang, S.-Y. Yang, C.-C. M. Ma and Y.-F. Wu, ACS Appl. Mater. Interfaces, 2013, 5, 3975-3982.

26 C.-W. Lin, C.-W. Lou, C.-H. Huang, C.-L. Huang and J.-H. Lin, J. Thermoplast. Compos. Mater., 2014, 27, 14511460. 
27 F. Rezaei, R. Yunus and N. A. Ibrahim, Mater. Des., 2009, 30, 260-263.

28 A. S. Babal, B. P. Singh and V. N. Singh, RSC Adv., 2014, 4, 64649-64658.

29 K. Seo, L. Park, J.-B. Baek and W. Brostow, Polymer, 1993, 34, 2524-2527.

30 P. Garg, B. P. Singh, G. Kumar, T. Gupta, I. Pandey, R. Seth, R. Tandon and R. B. Mathur, J. Polym. Res., 2011, 18, 13971407.

31 P. Ciselli, Z. Wang and T. Peijs, Mater. Sci. Technol., 2007, 22, 10-21.

32 B. P. Singh, S. Teotia, T. K. Gupta, V. N. Singh, S. R. Dhakate and R. B. Mathur, Adv. Mater. Lett., 2015, 6, 104-113.

33 A. Ameli, P. Jung and C. Park, Carbon, 2013, 60, 379-391.

34 M.-S. Hong, W.-K. Choi, K.-H. An, S.-J. Kang, S.-J. Park, Y. S. Lee and B.-J. Kim, J. Ind. Eng. Chem., 2014, 20, 39013904.

35 S. Rahmanian, K. Thean, A. Suraya, M. Shazed, M. M. Salleh and H. Yusoff, Mater. Des., 2013, 43, 10-16.

36 F. Puch and C. Hopmann, Polymer, 2014, 55, 3015-3025.
37 T. K. Gupta, B. P. Singh, S. R. Dhakate, V. N. Singh and R. B. Mathur, J. Mater. Chem. A, 2013, 1, 9138-9149.

38 B. P. Singh, D. Singh, R. B. Mathur and T. Dhami, Nanoscale Res. Lett., 2008, 3, 444.

39 A. S. Babal, R. Gupta, B. P. Singh and S. R. Dhakate, RSC Adv., 2015, 5, 43462-43472.

40 Y. M. Boiko, W. Brostow, A. Y. Goldman and A. Ramamurthy, Polymer, 1995, 36, 1383-1392.

41 S. Pande, A. Chaudhary, D. Patel, B. P. Singh and R. B. Mathur, $R S C A d v ., 2014$, 4, 13839-13849.

42 J. Jyoti, B. P. Singh, A. K. Arya and S. R. Dhakate, RSC Adv., 2016, 6, 3997-4006.

43 L. A. Pothan, Z. Oommen and S. Thomas, Compos. Sci. Technol., 2003, 63, 283-293.

44 Z. Oommen, G. Groeninckx and S. Thomas, J. Polym. Sci., Part B: Polym. Phys., 2000, 38, 525-536.

45 L. Bokobza, J.-L. Bruneel and M. Couzi, Chem. Phys. Lett., 2013, 590, 153-159.

46 L. Bokobza, J.-L. Bruneel and M. Couzi, Vib. Spectrosc., 2014, 74, 57-63. 